\title{
Low-Profile Equiangular Spiral Antenna Backed by an EBG Reflector
}

\author{
Hisamatsu Nakano, Fellow, IEEE, Katsuki Kikkawa, Norihiro Kondo, Yasushi Iitsuka, Member, IEEE, and \\ Junji Yamauchi, Member, IEEE
}

\begin{abstract}
The bi-directional beam from an equiangular spiral antenna (EAS) is changed to a unidirectional beam using an electromagnetic band gap (EBG) reflector. The antenna height, measured from the upper surface of the EBG reflector to the spiral arms, is chosen to be extremely small to realize a low-profile antenna: 0.07 wavelength at the lowest analysis frequency of 3 GHz. The analysis shows that the EAS backed by the EBG reflector does not reproduce the inherent wideband axial ratio characteristic observed when the EAS is isolated in free space. The deterioration in the axial ratio is examined by decomposing the total radiation field into two field components: one component from the equiangular spiral and the other from the EBG reflector. The examination reveals that the amplitudes and phases of these two field components do not satisfy the constructive relationship necessary for circularly polarized radiation. Based on this finding, next, the EBG reflector is modified by gradually removing the patch elements from the center region of the reflector, thereby satisfying the required constructive relationship between the two field components. This equiangular spiral with a modified EBG reflector shows wideband characteristics with respect to the axial ratio, input impedance and gain within the design frequency band (4-9 GHz). Note that, for comparison, the antenna characteristics for an EAS isolated in free space and an EAS backed by a perfect electric conductor are also presented.
\end{abstract}

Index Terms-Electromagnetic band gap (EBG) reflector, equiangular spiral, extremely low-profile structure, wideband operation.

\section{INTRODUCTION}

I T IS KNOWN that an equiangular spiral (EAS) antenna isolated in free space (referred to as the $\mathrm{EAS}_{\text {free }}$ ) operates as a wideband antenna that radiates a bi-directional circularly polarized (CP) beam [1]. Recent theoretical/numerical studies have shown that when the EAS is backed by an extremely shallow conducting cavity ( 0.07 wavelength [2]), which transforms the bi-directional beam into a unidirectional beam, the inherent wideband antenna characteristics deteriorate. To mitigate this deterioration, the authors have proposed the insertion of arc-shaped strip absorbers (ABSs) into the cavity [2].

Manuscript received April 12, 2008; revised July 22, 2008. Current version published May 06, 2009.

H. Nakano, N. Kondo, Y. Iitsuka, and J. Yamauchi are with the College of Engineering, Hosei University, Koganei, Tokyo, Japan 184-8584 (e-mail: hymat@ hosei.ac.jp).

K. Kikkawa was with the College of Engineering, Hosei University, Koganei, Tokyo, Japan 184-8584. He is now with Yokogawa Electric Corporation, Tokyo 180-8750, Japan.

Color versions of one or more of the figures in this paper are available online at http://ieeexplore.ieee.org.

Digital Object Identifier 10.1109/TAP.2009.2016697
It has been shown that the ABSs contribute to restoring the inherent wideband EAS antenna characteristics. However, this is achieved at the cost of radiation efficiency, because some of the power is absorbed by the ABSs.

This paper solves the abovementioned issue regarding the frequency characteristics of the low-profile equiangular spiral antenna (whose height is less than one-quarter wavelength), without using ABSs. For this solution, an electromagnetic band gap (EBG) plate [3] is used as a reflector in place of the conducting cavity. The equiangular spiral with an EBG reflector is referred to as the $\mathrm{EAS}_{\mathrm{EBG}}$ in this paper.

The prototype of $\mathrm{EAS}_{\mathrm{EBG}}$ is investigated using the finite-difference time-domain method (FDTDM) [4], where an analysis frequency range of $3-10 \mathrm{GHz}$ is used for the prototype to operate within a frequency range of 4-9 GHz (which is designated as the operating design frequency band; for use within a different operating design frequency band, the prototype is simply scaled up or down to match the desired frequency band). It is emphasized that the antenna height $h_{E B G}$ (the distance from the upper surface of the EBG reflector to the spiral arms) is chosen to be extremely small, to realize a low-profile antenna; $\mathrm{h}_{\mathrm{EBG}}=7 \mathrm{~mm}$ (0.07 wavelength at the lowest analysis frequency of $3 \mathrm{GHz}$ ). This small antenna height reduces the bulkiness of the EAS, making it suitable for installation on the roof of a vehicle or on the wall of a building. Note that the low-profile EAS discussed in this paper can be used as a radar antenna that performs wide frequency scanning, a wideband satellite-mobile communication antenna, and a wideband point-to-point communication antenna.

The three sections followed by this introduction constitute the main part of this paper. Section II describes the configuration of the equiangular spiral to be considered. Section III starts with a brief summary of the analysis method for the equiangular spiral, and then presents analysis results. The discussion for the analysis results is given in three Sections III-A, III-B, and III-C.

For clarifying issues encountered when the antenna height is reduced, Section III-A refers to the axial ratio of a low-profile equiangular spiral backed by a reflector made of a perfect electric conductor (PEC). This antenna structure is referred to as the $\mathrm{EAS}_{\mathrm{PEC}}$. The analysis reveals that the low-profile $\mathrm{EAS}_{\mathrm{PEC}}$ does not have a small axial ratio (required for a $\mathrm{CP}$ antenna) over a wide frequency range. In Section III-B, an EBG reflector is used in place of the PEC reflector and the axial ratio of this antenna structure $\left(\mathrm{EAS}_{\mathrm{EBG}}\right)$ is analyzed, in an effort to realize a wideband CP antenna. However, the low-profile $\mathrm{EAS}_{\mathrm{EBG}}$ does not show improvement in the frequency response of the axial ratio. The reason why the axial ratio is not improved is explained by decomposing the total radiation field into two radiation field 


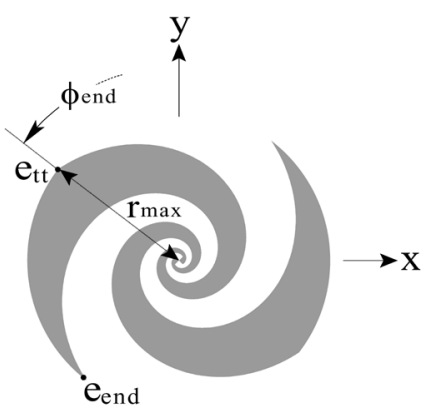

(a)

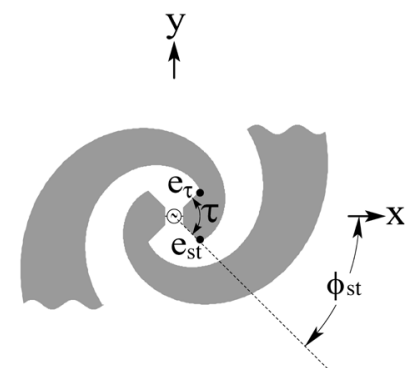

(b)

Fig. 1. Equiangular spiral. (a) Top view. (b) Feed area.

components: one component from the equiangular spiral and the other from the EBG reflector.

Considering the fields from the abovementioned field decomposition, Section III-C proposes modification of the EBG reflector in order to improve the axial ratio. This modification is performed by gradually removing the patches (which constitute the EBG reflector) from the center region of the EBG reflector. Such a technique has been applied to some antennas [5]-[7] for improving the antenna characteristics. However, the axial ratio of a CP antenna with a modified EBG reflector has not been discussed. Note that patch removal leads to a new structure composed of an excited radiation element and parasitic EBG-patch elements, whose number is finite, and hence this structure must be investigated as a compound antenna.

We designate an equiangular spiral with a modified EBG reflector as $\mathrm{EAS}_{\mathrm{MD}-\mathrm{EBG}}$. The frequency responses of the antenna characteristics of the $\mathrm{EAS}_{\mathrm{MD}-\mathrm{EBG}}$, including the axial ratio, radiation pattern, input impedance, and gain, are analyzed, and finally a low-profile wideband equiangular spiral antenna is realized.

Section IV summarizes the results obtained in this paper. Note that each suffix of the abbreviations $\mathrm{EAS}_{\text {free }}, \mathrm{EAS}_{\mathrm{PEC}}$, $\mathrm{EAS}_{\mathrm{EBG}}$, and $\mathrm{EAS}_{\mathrm{MD}-\mathrm{EBG}}$ appearing in this paper designates the material under the equiangular spiral arms.

\section{CONFIGURATION}

Our goal is to design a circularly polarized low-profile equiangular spiral antenna that operates from $\mathrm{f}_{\mathrm{L}}=4 \mathrm{GHz}$ to $\mathrm{f}_{\mathrm{H}}=9 \mathrm{GHz}$ (the operating design frequency band). For this, the lowest analysis frequency is chosen to be $\mathrm{f}_{\mathrm{La}}=3 \mathrm{GHz}$ (below $\mathrm{f}_{\mathrm{L}}=4 \mathrm{GHz}$ ) and the highest analysis frequency is chosen to be $\mathrm{f}_{\mathrm{Ha}}=10 \mathrm{GHz}\left(\right.$ above $\left.\mathrm{f}_{\mathrm{H}}=9 \mathrm{GHz}\right)$.

Fig. 1 shows the configuration of the equiangular spiral antenna. The two arms are symmetric with respect to the center and are wound to be self-complementary [8]. These spiral arms
TABLE I

\begin{tabular}{ccc}
\multicolumn{3}{c}{ CONFIGURATION PARAMETERS } \\
\hline symbol & value & unit \\
\hline $\mathrm{r}_{0}$ & 1.5 & $\mathrm{~mm}$ \\
$a$ & 0.35 & $\mathrm{rad}^{-1}$ \\
$\phi_{s t}$ & $-0.25 \pi$ & $\mathrm{rad}$ \\
$\phi_{\text {end }}$ & $2.806 \pi$ & $\mathrm{rad}$ \\
$\tau$ & $0.5 \pi$ & $\mathrm{rad}$ \\
\hline
\end{tabular}

are truncated at radial distance $r_{\max }$. The edge $e_{s t}-e_{t t}$ is defined by radial distance $\mathrm{r}=\mathrm{r}_{0} \mathrm{e}^{\mathrm{a}\left(\phi^{\prime}+\pi / 2\right)}$, where $\mathrm{r}_{0}$ is a constant; $a$ is the arm growth constant; and $\phi^{\prime}$ is the winding angle, ranging from $\phi_{\text {st }}$ radians to $\phi_{\text {end }}$ radians. The truncated edge $\mathrm{e}_{\mathrm{tt}}-\mathrm{e}_{\mathrm{end}}$ is defined by a radius of $\mathrm{r}_{\max }=\mathrm{r}_{0} \mathrm{e}^{\mathrm{a}\left(\phi_{\mathrm{end}}+\pi / 2\right)}$. The edge $e_{\tau}-e_{\text {end }}$ is obtained by rotating the edge $e_{s t}-e_{t t}$ by $\tau$ radians. The configuration parameters are summarized in Table I [1] and remain the same throughout this paper to simplify the discussion. Note that the antenna circumference, defined as $2 \pi \mathrm{r}_{\max }$, is more than one wavelength at the lower operating design frequency $\mathrm{f}_{\mathrm{L}}(=4 \mathrm{GHz})$, so that an active region will exist at this frequency [9].

\section{DISCUSSION}

Brief comments are made for the analysis method. The antenna characteristics in this paper are analyzed on the basis of the electric $(\mathbf{E})$ and magnetic $(\mathbf{H})$ fields that are obtained using the finite-difference time-domain method (FDTDM). The $\mathrm{x}$ and $\mathrm{y}$ components of the fields $\mathbf{E}$ and $\mathbf{H}$ for the equiangular spiral have even-symmetry relationships: $\mathrm{E}_{\mathrm{m}}(\mathrm{x}, \mathrm{y}, \mathrm{z})=\mathrm{E}_{\mathrm{m}}(-\mathrm{x},-\mathrm{y}, \mathrm{z})$ and $\mathrm{H}_{\mathrm{m}}(\mathrm{x}, \mathrm{y}, \mathrm{z})=$ $\mathrm{H}_{\mathrm{m}}(-\mathrm{x},-\mathrm{y}, \mathrm{z})$, where $\mathrm{m}=\mathrm{x}$ or $\mathrm{y}$. The $\mathrm{z}$-components have odd-symmetry relationships: $\mathrm{E}_{\mathrm{z}}(\mathrm{x}, \mathrm{y}, \mathrm{z})=-\mathrm{E}_{\mathrm{z}}(-\mathrm{x},-\mathrm{y}, \mathrm{z})$ and $\mathrm{H}_{\mathrm{z}}(\mathrm{x}, \mathrm{y}, \mathrm{z})=-\mathrm{H}_{\mathrm{z}}(-\mathrm{x},-\mathrm{y}, \mathrm{z})$. The use of these symmetry relationships reduces the FDTDM computational burden.

The current density on a conducting plate, $\mathrm{J}_{\mathrm{m}}$ (where $\mathrm{m}=\mathrm{x}$ or $y$ ), is obtained from the magnetic field component on the plate surface, $\mathrm{H}_{\mathrm{s}, \mathrm{m}}$. This component is not assigned in Yee's FDTDM cell [4], and hence $\mathrm{H}_{\mathrm{s}, \mathrm{m}}$ must be obtained by extrapolating two magnetic field components (parallel to the plate) near the conductor surface [10]

$$
\begin{aligned}
\mathrm{H}_{\mathrm{s}, \mathrm{x}}= & +1.5 \mathrm{H}_{\mathrm{x}}(\mathrm{i}, \mathrm{j}+1 / 2, \mathrm{k}+1 / 2) \\
& -0.5 \mathrm{H}_{\mathrm{x}}(\mathrm{i}, \mathrm{j}+1 / 2, \mathrm{k}+3 / 2) \\
\mathrm{H}_{\mathrm{s}, \mathrm{y}}= & +1.5 \mathrm{H}_{\mathrm{y}}(\mathrm{i}+1 / 2, \mathrm{j}, \mathrm{k}+1 / 2) \\
& -0.5 \mathrm{H}_{\mathrm{y}}(\mathrm{i}+1 / 2, \mathrm{j}, \mathrm{k}+3 / 2) .
\end{aligned}
$$

The radiation field $\mathbf{E}_{\mathrm{rad}}$ in the spherical coordinate system $(\mathrm{r}, \theta, \phi)$ has two components: $\mathrm{E}_{\theta}$ and $\mathrm{E}_{\phi}$. These are calculated using the equivalence principle [11] and then decomposed into a right-hand $\mathrm{CP}$ wave component $\mathrm{E}_{\mathrm{R}}$ (complex number) and a left-hand $\mathrm{CP}$ wave component $\mathrm{E}_{\mathrm{L}}$ (complex number) for calculating the axial ratio: $A R=\left(\left|\mathrm{E}_{\mathrm{R}}\right|+\left|\mathrm{E}_{\mathrm{L}}\right|\right) /\left(\left|\mathrm{E}_{\mathrm{R}}\right|-\left|\mathrm{E}_{\mathrm{L}}\right|\right)$, where $\left|E_{R}\right|$ is greater than $\left|E_{L}\right|$ in the positive z-direction for the equiangular spiral shown in Fig. 1. The absolute gain relative to a right-hand $\mathrm{CP}$ isotropic antenna is given as $\mathrm{G}_{\mathrm{R}}=$ $\mathrm{G} /\left[1+\left(\xi_{-} / \xi_{+}\right)^{2}\right]$, and the absolute gain relative to a left-hand 


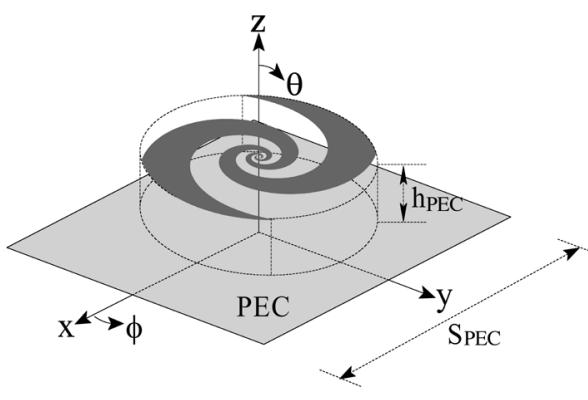

Fig. 2. Equiangular spiral above a PEC reflector $\left(E_{A S} S_{P E C}\right)$.

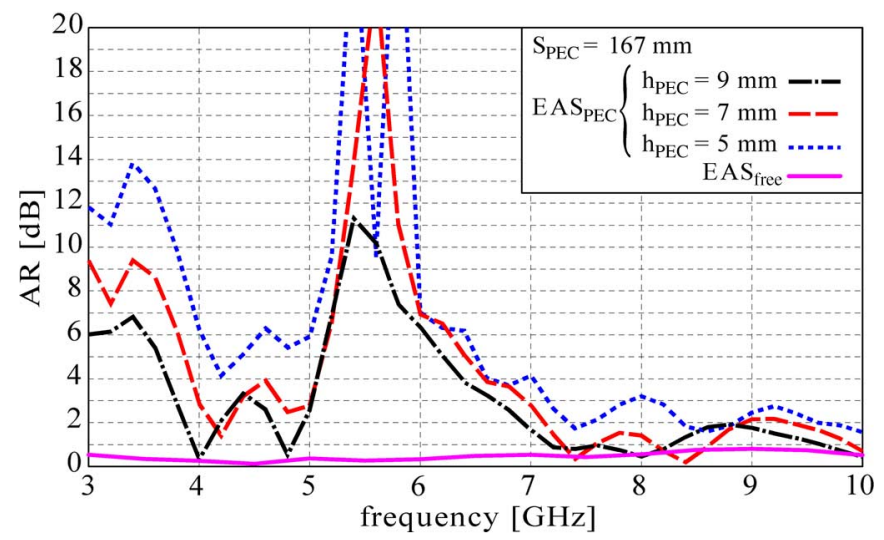

Fig. 3. Frequency response of the axial ratio for the EAS $\mathrm{PEC}_{\mathrm{PEC}}$, with antenna height $h_{P E C}$ as a parameter, where the side length of the square PEC reflector is $\mathrm{S}_{\mathrm{PEC}}=167 \mathrm{~mm}$. The axial ratio for the $\mathrm{EAS}_{\text {free }}$ is also depicted in this figure.

$\mathrm{CP}$ isotropic antenna is given as $\mathrm{G}_{\mathrm{L}}=\mathrm{G} /\left[1+\left(\xi_{+} / \xi_{-}\right)^{2}\right]$, where $\xi_{ \pm}$are defined as $\xi_{ \pm}=\mathrm{AR} \pm 1 ; \mathrm{G}$ is defined as $\mathrm{G}=$ $\left\{\left(\left|\mathrm{E}_{\theta}\right|^{2}+\left|\mathrm{E}_{\phi}\right|^{2}\right) / 2 \mathrm{Z}_{0}\right\} /\left(\mathrm{P}_{\text {in }} / 4 \pi \mathrm{r}^{2}\right)$, where $\mathrm{Z}_{0}$ is the intrinsic impedance of free space $(120 \pi$ ohms $)$ and $\mathrm{P}_{\text {in }}$ is the power observed at the antenna input (at the center terminals where the voltage source is connected).

\section{A. Equiangular Spiral With a PEC Reflector (EASPEC)}

A bi-directional beam can be transformed into a unidirectional beam by placing a plate that is a perfect electric conductor (PEC) [12], [13] behind the radiation element. Based on this simple idea, first, we analyze an equiangular spiral

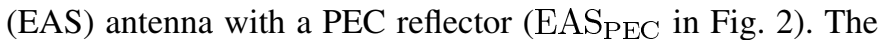
PEC reflector is square with side length $\mathrm{S}_{\mathrm{PEC}}$ and the antenna arms are located at height $h_{\mathrm{PEC}}$ above the reflector surface. We determine the antenna characteristics when the antenna height $\mathrm{h}_{\mathrm{PEC}}$ is small and use them as a reference in the subsequent subsections.

Fig. 3 shows the frequency response of the axial ratio (AR) in the positive z-direction, with antenna height $h_{\mathrm{PEC}}$ as a parameter, where the PEC reflector has a side length of $\mathrm{S}_{\mathrm{PEC}}=$ $167 \mathrm{~mm}\left(\equiv \mathrm{S}_{\mathrm{PEC}, 0}\right)$, which is greater than the diameter of the spiral $2 \mathrm{r}_{\max }$ (with $2 \mathrm{r}_{\max } / \mathrm{S}_{\mathrm{PEC}, 0} \approx 0.68$ ). Three representative cases, each having small antenna height $\left(\mathrm{h}_{\mathrm{PEC}}=5 \mathrm{~mm}, 7 \mathrm{~mm}\right.$, and $9 \mathrm{~mm}$, which are all less than one quarter wavelength at the lower operating design frequency $\mathrm{f}_{\mathrm{L}}=4 \mathrm{GHz}$ ), are presented

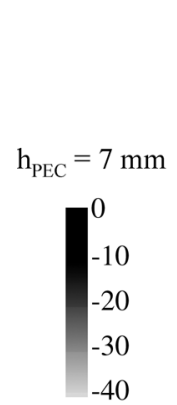

$[\mathrm{dB}]$

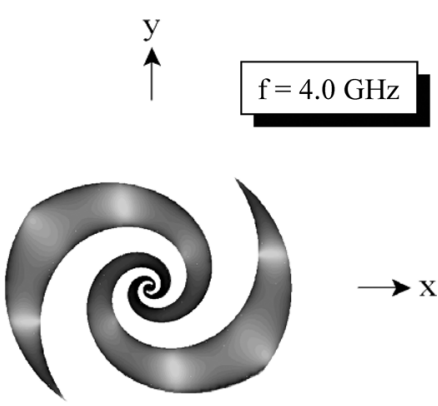

(a)

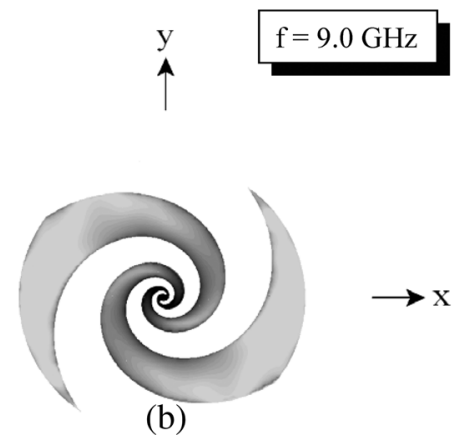

Fig. 4. Current distributions for the $\mathrm{EAS}_{\mathrm{PEC}}$, where $\mathrm{h}_{\mathrm{PEC}}=7 \mathrm{~mm}$ and $\mathrm{S}_{\mathrm{PEC}}=167 \mathrm{~mm}$. (a) At $4 \mathrm{GHz}$. (b) At $9 \mathrm{GHz}$.

in this figure. For reference, the AR in the absence of the PEC reflector $\left(\mathrm{EAS}_{\text {free }}\right)$ is also shown.

Fig. 3 reveals that as the antenna height $h_{\mathrm{PEC}}$ is decreased, variation in the AR becomes noticeable at frequencies below $7 \mathrm{GHz}$. This variation is due to generation of an undesirable cross-polarization component $\mathrm{E}_{\mathrm{L}}$, which is produced from a current flowing toward the feed point (in-coming current). Note that a current flowing from the feed point toward the arm ends (out-going current) radiates a desired right-hand $\mathrm{CP}$ wave (principal radiation field component $\mathrm{E}_{\mathrm{R}}$ ).

Fig. 4 shows the current distributions along the antenna arms at the lower design frequency of $\mathrm{f}_{\mathrm{L}}=4 \mathrm{GHz}$ [Fig. 4(a)] and the upper design frequency of $\mathrm{f}_{\mathrm{H}}=9 \mathrm{GHz}$ [Fig. 4(b)], where the side length of the $\mathrm{PEC}$ reflector is $\mathrm{S}_{\mathrm{PEC}}=\mathrm{S}_{\mathrm{PEC}, 0}(=167 \mathrm{~mm})$ and the antenna height is $h_{\mathrm{PEC}}=7 \mathrm{~mm}$. The current distribution at $\mathrm{f}_{\mathrm{L}}=4 \mathrm{GHz}$ shows a standing wave. This means that the current is composed of out-going and in-coming currents, and the axial ratio deteriorates due to the presence of the in-coming current. On the other hand, the current distribution at $\mathrm{f}_{\mathrm{H}}=9 \mathrm{GHz}$ is governed by the out-going current and hence the EAS $\mathrm{PEC}_{\mathrm{P}}$ radiates a $\mathrm{CP}$ wave, as desired. Note that as the antenna height $h_{\mathrm{PEC}}$ is decreased, the input impedance also deteriorates due to the generation of the in-coming current.

Our final objective in this paper is to construct a low-profile equiangular spiral antenna that operates as a $\mathrm{CP}$ antenna within a given wide frequency band (design frequency band: 4-9 GHz). For this, we use an analysis frequency range of 3-10 GHz, focusing on one of the small antenna heights in Fig. 3: $7 \mathrm{~mm}=$ $0.07 \lambda_{3} \equiv \mathrm{h}_{\text {test }}$, where $\lambda_{\mathrm{n}}$ is the notation for the free space wavelength at $\mathrm{n} \mathrm{GHz}$. Note that other low-profile equiangular spirals with different antenna heights can be designed in a similar fashion. 


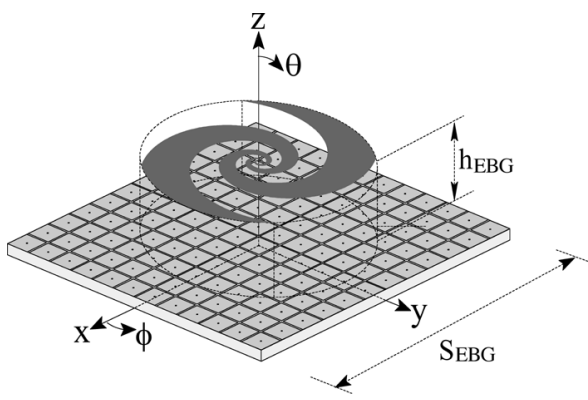

(a)

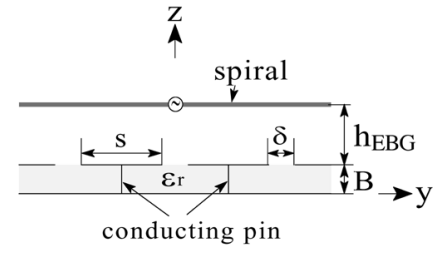

(b)

Fig. 5. Equiangular spiral antenna above an $\mathrm{EBG}$ reflector $\left(\mathrm{EAS}_{\mathrm{EBG}}\right)$.

\section{B. Equiangular Spiral With an EBG Reflector $\left(\mathrm{EAS}_{\mathrm{EBG}}\right)$}

An EBG reflector has a reflection coefficient of $\Gamma=+1$ at its surface [3]. Therefore, we would expect that, at frequencies near the frequency that satisfies $\Gamma=+1$, the antenna characteristics do not deteriorate when the antenna height is reduced. So far, this expectation has been confirmed for thin wire antennas backed by an EBG reflector, such as dipole, curl, and small Archimedean spiral antennas [14], [15].

The question arises of whether the EBG reflector can work for an antenna whose arms are composed of wide conducting strips, such as the arms of the equiangular spiral. In other words, can the antenna characteristics of the EASPEC, discussed in Section III-A, be improved by replacing the PEC reflector with the EBG reflector?

To investigate this, we apply an EBG reflector to the equiangular spiral and obtain the antenna characteristics. Fig. 5 shows the configuration of the equiangular spiral backed by an EBG reflector $\left(\mathrm{EAS}_{\mathrm{EBG}}\right)$, where the distance between the spiral and the upper surface of the EBG reflector (referred to as the antenna height) is denoted as $h_{\mathrm{EBG}}$.

The EBG reflector is composed of $\mathrm{N}_{\max } \times \mathrm{N}_{\max }$ patches and is square, with side length $\mathrm{S}_{\mathrm{EBG}}\left[=\mathrm{sN}_{\max }+\left(\mathrm{N}_{\max }-\right.\right.$ 1) $\delta$, where $s$ is the side length of a single patch (square patch) and $\delta$ is the spacing between neighboring patches. The bottom of the EBG reflector is a square PEC plate whose side length equals $\mathrm{S}_{\mathrm{EBG}}$. The patches are printed on a dielectric substrate of relative permittivity $\varepsilon_{\mathrm{r}}$ and thickness $B$. Note that each patch is short-circuited to the bottom PEC plate of the EBG reflector with a conducting pin.

The EBG reflector is designed such that the reflection phase at a given frequency $\mathrm{f}_{\mathrm{EBG}}$ is zero for a plane wave normally illuminating the EBG reflector [3]. Fig. 6 shows three EBG reflectors, designed for $\mathrm{f}_{\mathrm{EBG} 1}=3.8 \mathrm{GHz}, \mathrm{f}_{\mathrm{EBG} 2}=5.1 \mathrm{GHz}$, and $\mathrm{f}_{\mathrm{EBG} 3}=6.1 \mathrm{GHz}$, where the patch side length $\mathrm{s}$ is $19 \mathrm{~mm}$ for $\mathrm{f}_{\mathrm{EBG} 1}, 13 \mathrm{~mm}$ for $\mathrm{f}_{\mathrm{EBG} 2}$, and $10 \mathrm{~mm}$ for $\mathrm{f}_{\mathrm{EBG} 3}$, and the spacing between neighboring patches $\delta$ is all $1 \mathrm{~mm}$. Note that these are calculated using a periodical boundary condition for

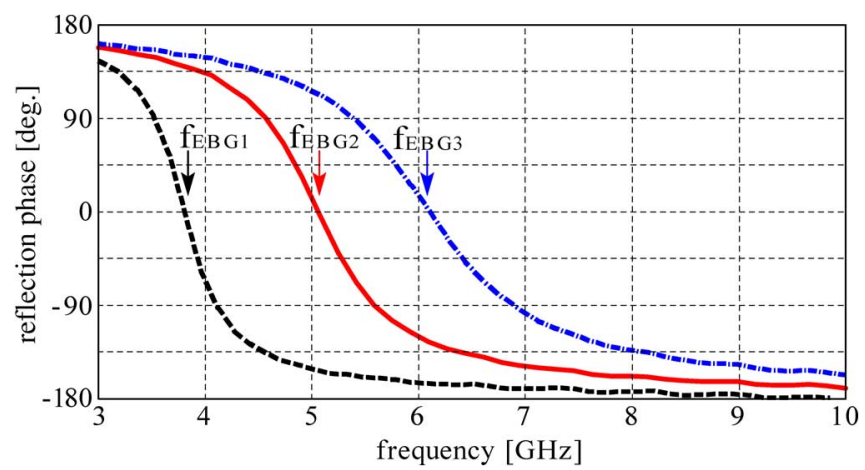

Fig. 6. Reflection phase of the EBG reflector, where $\varepsilon_{\mathrm{r}}=2.2, \mathrm{~B}=2 \mathrm{~mm}$, and $\delta=1 \mathrm{~mm}$. The zero reflection phase is obtained at frequency $\mathrm{f}_{\mathrm{EBG} 1}=$ $3.8 \mathrm{GHz}$ for $\mathrm{s}=19 \mathrm{~mm}, \mathrm{f}_{\mathrm{EBG} 2}=5.1 \mathrm{GHz}$ for $\mathrm{s}=13 \mathrm{~mm}$, and $\mathrm{f}_{\mathrm{EBG} 3}=$ 6.1 $\mathrm{GHz}$ for $\mathrm{s}=10 \mathrm{~mm}$. Periodical boundary condition for $\mathrm{N}_{\max }=\infty$ is used.

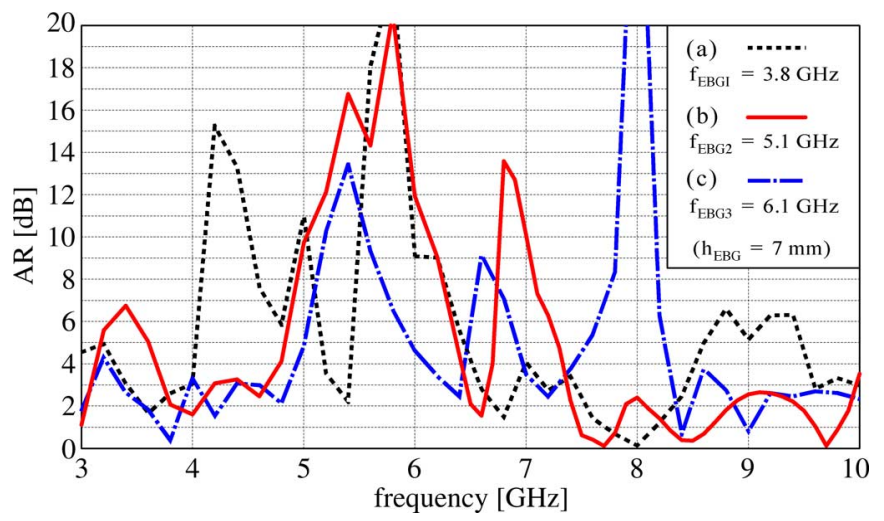

Fig. 7. Axial ratio for the $\mathrm{EAS}_{\mathrm{EBG}}$. Curve (a) is for $\mathrm{S}_{\mathrm{EBG}}=159 \mathrm{~mm}$, $\mathrm{f}_{\mathrm{EBG}}=3.8 \mathrm{GHz} \equiv \mathrm{f}_{\mathrm{EBG} 1}, \mathrm{~s}=19 \mathrm{~mm}$, and $\mathrm{N}_{\max }=8$. Curve (b) is for $\mathrm{S}_{\mathrm{EBG}}=167 \mathrm{~mm}, \mathrm{f}_{\mathrm{EBG}}=5.1 \mathrm{GHz} \equiv \mathrm{f}_{\mathrm{EBG} 2}, \mathrm{~s}=13 \mathrm{~mm}$, and $\mathrm{N}_{\max }=12$. Curve (c) is for $\mathrm{S}_{\mathrm{EBG}}=175 \mathrm{~mm}, \mathrm{f}_{\mathrm{EBG}}=6.1 \mathrm{GHz} \equiv \mathrm{f}_{\mathrm{EBG} 3}$, $\mathrm{s}=10 \mathrm{~mm}$, and $\mathrm{N}_{\max }=16$. Parameters $\mathrm{h}_{\mathrm{EBG}}=7 \mathrm{~mm}, \varepsilon_{\mathrm{r}}=2.2$, $\mathrm{B}=2 \mathrm{~mm}$, and $\delta=1 \mathrm{~mm}$ are commonly used for curves (a)-(c).

$\mathrm{N}_{\max }=\infty$. Also note that the values of relative permittivity $\varepsilon_{\mathrm{r}}$ and thickness $B$ are chosen to be those of a commercially available dielectric substrate: $\varepsilon_{\mathrm{r}}=2.2$ and $\mathrm{B}=2 \mathrm{~mm}$.

Fig. 7 shows the frequency response of the axial ratio for the $\mathrm{EAS}_{\mathrm{EBG}}$, with $\mathrm{f}_{\mathrm{EBG}}$ as a parameter, where the antenna height $h_{\text {EBG }}$ is fixed to be $h_{\text {test }}(=7 \mathrm{~mm}$, as used in Section III-A), and the $\mathrm{EBG}$ side length is $\mathrm{S}_{\mathrm{EBG}}=\mathrm{S}_{\mathrm{PEC}, 0}-8 \mathrm{~mm}$ for curve (a), $\mathrm{S}_{\mathrm{EBG}}=\mathrm{S}_{\mathrm{PEC}, 0}$ for curve (b), and $\mathrm{S}_{\mathrm{EBG}}=\mathrm{S}_{\mathrm{PEC}, 0}+$ $8 \mathrm{~mm}$ for curve (c), where $S_{P E C, 0}=167 \mathrm{~mm}$. [Note: when the EBG reflector presented in Fig. 6 is finite-sized, the EBG side length $\mathrm{S}_{\mathrm{EBG}}$ (= the side length of a PEC plate constituting the $\mathrm{EBG}$ reflector) characterized by $\mathrm{f}_{\mathrm{EBG}}$ cannot necessarily equal $\mathrm{S}_{\mathrm{PEC}, 0}$; in such a case, $\mathrm{S}_{\mathrm{EBG}}$ is selected to be close to $\mathrm{S}_{\mathrm{PEC}, 0}$.] It is found that the axial ratio is not improved. The reason for this is explained in the following paragraphs, using radiation field decomposition.

We focus on a structure with $\mathrm{S}_{\mathrm{EBG}}=\mathrm{S}_{\mathrm{PEC}, 0}$, which gives a solid curve (b) in Fig. 7. As seen from the curve, the axial ratios in the positive z-direction at frequencies between $5 \mathrm{GHz}$ and $6 \mathrm{GHz}$ are undesirably high. The top row of Fig. 8 shows the (total) radiation field at $5.6 \mathrm{GHz}$, where the (total) radiation field is expressed by two components, $\mathrm{E}_{\mathrm{R}}\left(=\left|\mathrm{E}_{\mathrm{R}}\right| \mathrm{e}^{\mathrm{j} \phi_{\mathrm{R}}}\right)$ and $\mathrm{E}_{\mathrm{L}}$ 


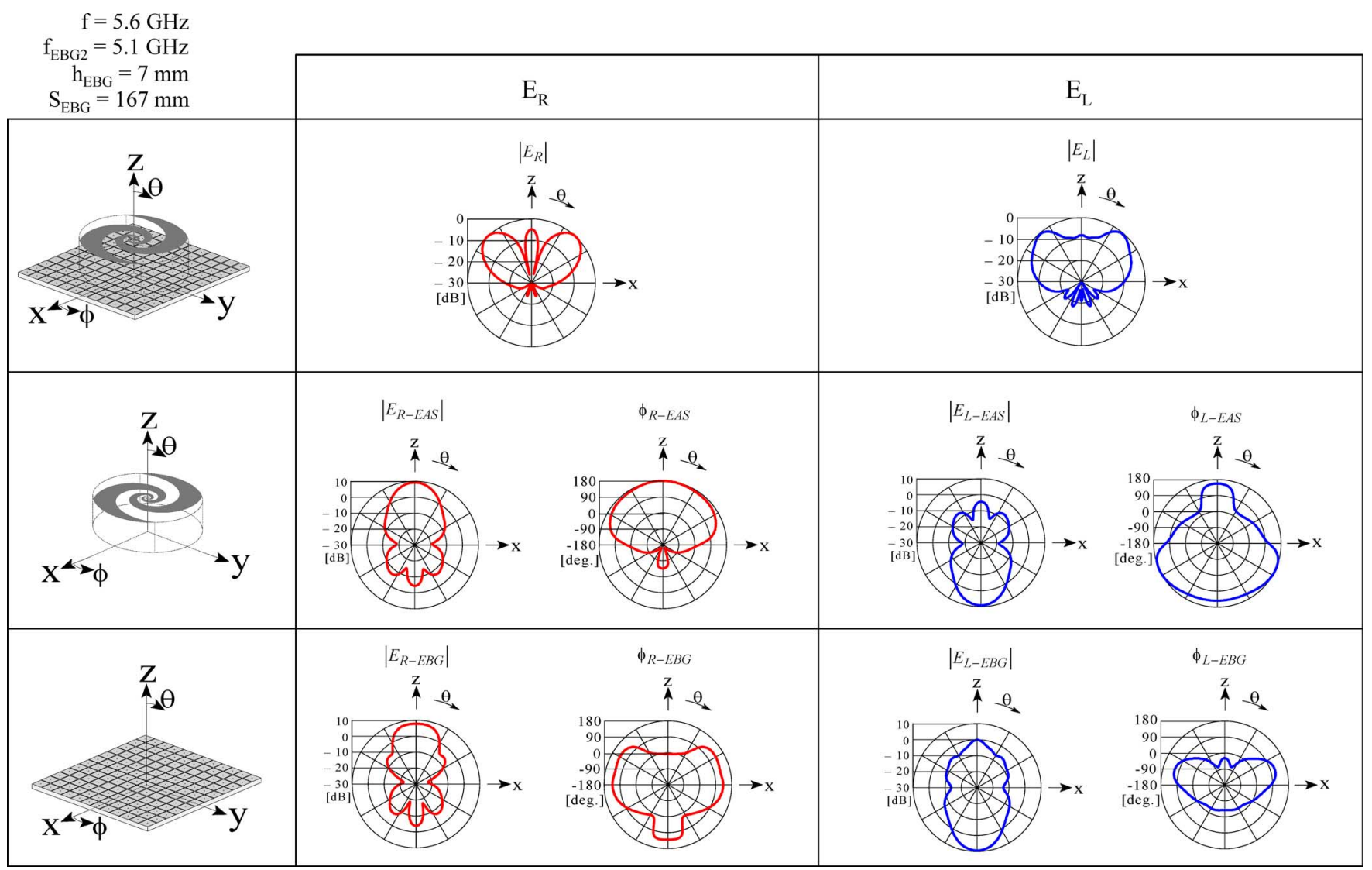

Fig. 8. Radiation field decomposition for the $\mathrm{EAS}_{\mathrm{EBG}}$ at $5.6 \mathrm{GHz}$, where $\mathrm{h}_{\mathrm{EBG}}=7 \mathrm{~mm}, \mathrm{~S}_{\mathrm{EBG}}=167 \mathrm{~mm}, \mathrm{f}_{\mathrm{EBG}}=5.1 \mathrm{GHz} \equiv \mathrm{f}_{\mathrm{EBG} 2}, \mathrm{~s}=13 \mathrm{~mm}$, $\varepsilon_{\mathrm{r}}=2.2, \mathrm{~B}=2 \mathrm{~mm}, \delta=1 \mathrm{~mm}$, and $\mathrm{N}_{\max }=12$.

$\left(=\left|\mathrm{E}_{\mathrm{L}}\right| \mathrm{e}^{\mathrm{j} \phi_{\mathrm{L}}}\right)$. Each of these components is further decomposed into two radiation fields

$$
\begin{aligned}
\left|\mathrm{E}_{\mathrm{R}}\right| \mathrm{e}^{\mathrm{j} \phi_{\mathrm{R}}} & =\left|\mathrm{E}_{\mathrm{R}-\mathrm{EAS}}\right| \mathrm{e}^{\mathrm{j} \phi_{\mathrm{R}-\mathrm{EAS}}}+\left|\mathrm{E}_{\mathrm{R}-\mathrm{EBG}}\right| \mathrm{e}^{\mathrm{j} \phi_{\mathrm{R}-\mathrm{EBG}}} \\
\left|\mathrm{E}_{\mathrm{L}}\right| \mathrm{e}^{\mathrm{j} \phi_{\mathrm{L}}} & =\left|\mathrm{E}_{\mathrm{L}-\mathrm{EAS}}\right| \mathrm{e}^{\mathrm{j} \phi_{\mathrm{L}-\mathrm{EAS}}}+\left|\mathrm{E}_{\mathrm{L}-\mathrm{EBG}}\right| \mathrm{e}^{\mathrm{j} \phi_{\mathrm{L}-\mathrm{EBG}}}
\end{aligned}
$$

where the first term on the right side of each equation represents the radiation field from the equiangular spiral and the second term represents the radiation field from the EBG reflector. These radiation field components based on (3) and (4) are illustrated in the second and third rows of Fig. 8. Note that the EBG reflector used is the one specified by $\mathrm{f}_{\mathrm{EBG} 2}(\approx 5.1 \mathrm{GHz})$, and the amplitude of each radiation field is normalized to the maximum value of $E_{R}$.

For $\mathrm{CP}$ radiation, the amplitude $\left|\mathrm{E}_{\mathrm{L}}\right|$ should be negligibly small in the positive z-direction, compared with $\left|\mathrm{E}_{\mathrm{R}}\right|$. In addition, phases $\phi_{\mathrm{R}-\mathrm{EAS}}$ and $\phi_{\mathrm{R}-\mathrm{EBG}}$ should be in-phase and phases $\phi_{\mathrm{L}-\mathrm{EAS}}$ and $\phi_{\mathrm{L}-\mathrm{EBG}}$ should be out-of-phase. Unfortunately, these amplitude and phase relationships are not satisfied for the radiation fields shown in Fig. 8. As a result, the axial ratio in the z-direction is undesirably high.

Brief comments are added here on the calculation method used for Fig. 8. For the field calculation, first, the entire electric and magnetic (EM) fields within the antenna analysis space including the $\mathrm{EAS}_{\mathrm{EBG}}$ (original fields) are determined by using the FDTDM. Second, the radiation from the EAS $\mathrm{EBG}_{\mathrm{E}}$ is calculated using the equivalence principle [8], using some of the original fields that exist over a surface enclosing the $\mathrm{EAS}_{\mathrm{EBG}}$.
Third, the radiation from the equiangular spiral is calculated using the equivalence principle, using some of the original fields that exist over a surface enclosing only the spiral. Similarly, the radiation from the EBG reflector is calculated using some of the original fields that exist over a surface enclosing only the EBG reflector. Note that when the radiation from the spiral and that from the EBG reflector, obtained at the third stage, are added, the resulting radiation (field sum) reproduces the total radiation from the $\mathrm{EAS}_{\mathrm{EBG}}$, obtained at the second stage. This means that the total radiation from the $\mathrm{EAS}_{\mathrm{EBG}}$ is correctly decomposed into two field components, one from the spiral and one from the EBG reflector.

\section{Equiangular Spiral With a Modified EBG Reflector (EAS $\mathrm{MD-EBG})$}

The field decomposition in Section III-B describes the effect of the EBG reflector (located close to the equiangular spiral) on the total radiation field. In this subsection, we modify the original EBG reflector, as shown in Fig. 9, creating a space below the spiral by removing only the patches (the dielectric substrate remains). This space reduces the mutual effects between the antenna arms and the EBG reflector.

Removal of the EBG patches leads to a new (compound) structure, composed of a single excited radiation element and parasitic patch elements, whose number is finite. The currents distributed on these elements contribute to the total radiation field. The EBG reflector is optimized such that 


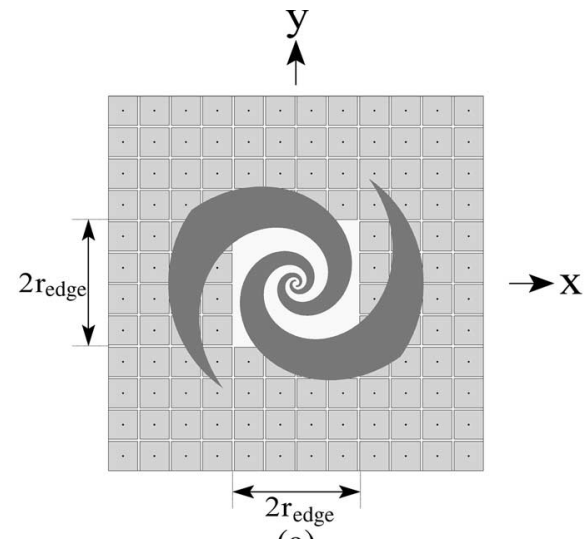

(a)

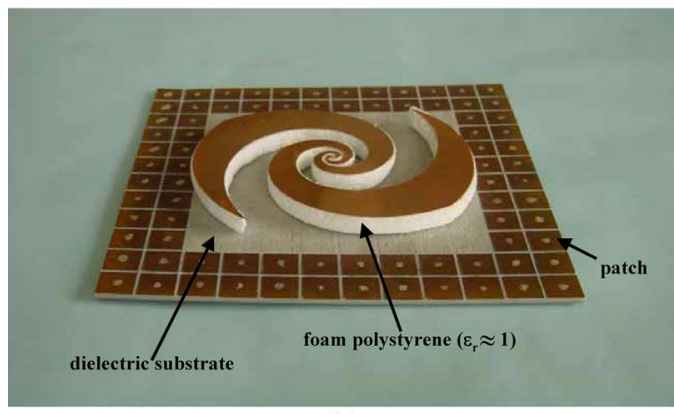

(b)

Fig. 9. Equiangular spiral backed by a modified EBG reflector $\left(\mathrm{EAS}_{\mathrm{MD}-\mathrm{EBG}}\right.$ ). (a) Top view. (b) Photo of EAS $\mathrm{SD}_{\mathrm{MD}-\mathrm{EBG}}$.

the principal radiation field component $\left(\mathrm{E}_{\mathrm{R}}\right)$ from the $\mathrm{EBG}$ reflector is constructively superposed on that from the equiangular spiral, having an in-phase (or semi-in-phase) relationship for $\mathrm{CP}$ radiation. To determine the number of patches that must be removed to satisfy this condition, $\mathrm{n}_{\mathrm{rmv}}^{2}$ patches are gradually removed from the center region of the EBG reflector; the number of remaining patches is then given as $\left(\mathrm{N}_{\max }\right)^{2}\left[1-\mathrm{n}_{\mathrm{rmv}}^{2} / \mathrm{N}_{\max }^{2}\right]$, where $\mathrm{n}_{\text {rmv }}$ and $\mathrm{N}_{\max }$ are even integers and the ratio $\mathrm{n}_{\mathrm{rmv}}^{2} / \mathrm{N}_{\max }^{2}$ is designated as the removal ratio $\mathrm{R}_{\mathrm{rmv}}$. The distance along the $\mathrm{x}$-axis or $\mathrm{y}$-axis from the EBG reflector center to the starting edge of the remaining patches is $r_{\text {edge }}=\left[n_{\mathrm{rmv}} \mathrm{s}+\left(\mathrm{n}_{\mathrm{rmv}}+1\right) \delta\right] / 2$. We designate the equiangular spiral with a modified EBG reflector as the EAS $_{\mathrm{MD}-\mathrm{EBG} \text {. }}$.

In the following paragraphs, we mitigate the deterioration in the axial ratio between $5 \mathrm{GHz}$ and $6 \mathrm{GHz}$, shown in Fig. 3, by modifying an $\mathrm{EBG}$ reflector with $\mathrm{f}_{\mathrm{EBG} 2}(\approx 5.1 \mathrm{GHz})$, while holding the distance between the upper surface of the EBG reflector and the antenna arms at $\mathrm{h}_{\mathrm{EBG}}=7 \mathrm{~mm}$. Fig. 10(a) shows the axial ratios in the positive z-direction, with the removal ratio $R_{r m v}$ as a parameter, where the number of patches is $\mathrm{N}_{\max }^{2}=12^{2}$ and the reflector side length is $\mathrm{S}_{\mathrm{EBG}}=\mathrm{S}_{\mathrm{PEC}, 0}$ $(=167 \mathrm{~mm})$. Note that the EAS $\mathrm{MD}_{\mathrm{EBG}}$ has a dielectric substrate on which patches are printed, even for $R_{\mathrm{rmv}}=1$.

As seen from Fig. 10(a), the large axial ratios observed at frequencies between $5 \mathrm{GHz}$ and $6 \mathrm{GHz}$ in Fig. 3 [which is again illustrated by a curve labeled EAS $\mathrm{PEC}_{\mathrm{P}}$ in Fig. 10(a)] can be decreased with appropriate removal of EBG patches $\left[\mathrm{R}_{\mathrm{rmv}}=\left(\mathrm{n}_{\mathrm{rmv}} / \mathrm{N}_{\max }\right)^{2}=(8 / 12)^{2}=0.44\right]$. As a result, the

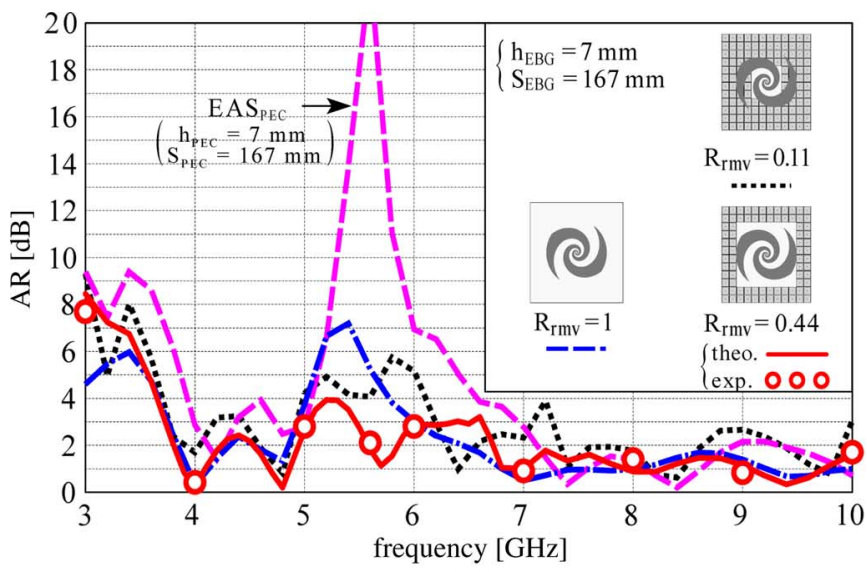

(a)

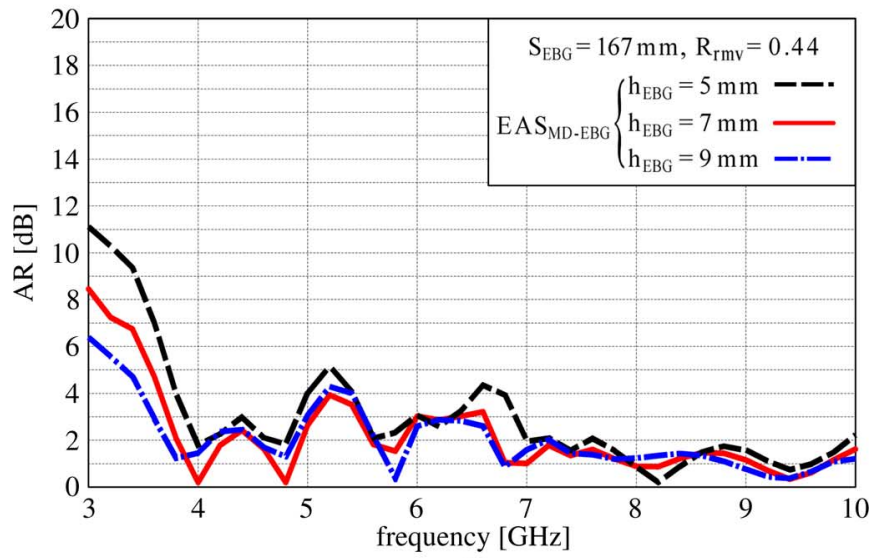

(b)

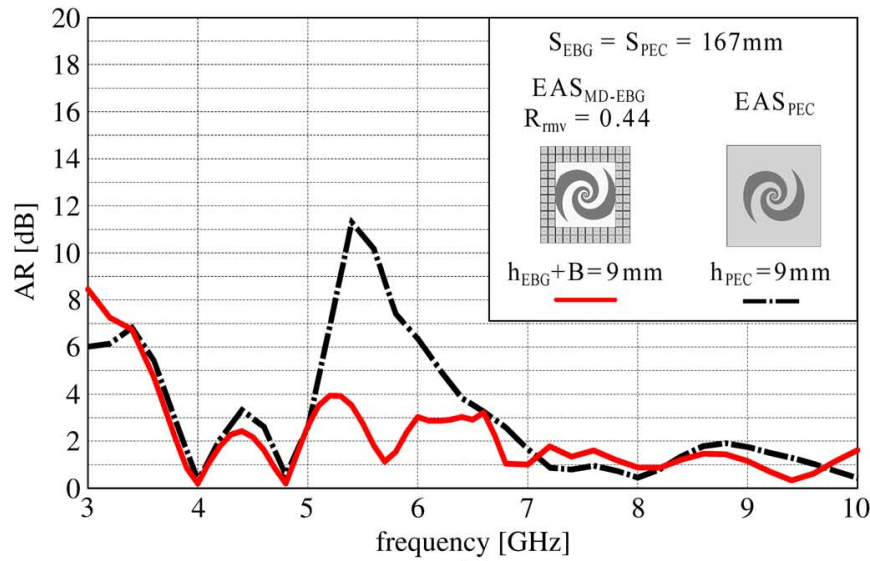

(c)

Fig. 10. Axial ratio for the $\mathrm{EAS}_{\mathrm{MD}-\mathrm{EBG}}$, where $\mathrm{S}_{\mathrm{EBG}}=167 \mathrm{~mm}, \mathrm{f}_{\mathrm{EBG}}=$ $5.1 \mathrm{GHz} \equiv \mathrm{f}_{\mathrm{EBG} 2}, \varepsilon_{\mathrm{r}}=2.2, \mathrm{~B}=2 \mathrm{~mm}, \delta=1 \mathrm{~mm}$, and $\mathrm{s}=13 \mathrm{~mm}$. (a) Axial ratio for $\mathrm{h}_{\mathrm{EBG}}=7 \mathrm{~mm}$ with removal ratio $\mathrm{R}_{\mathrm{rmv}}\left(\right.$ for $\mathrm{N}_{\max }=12$ ) as a parameter. (b) Axial ratio for $\mathrm{R}_{\mathrm{rmv}}=0.44$ (for $\mathrm{N}_{\max }=12$ ) with $\mathrm{h}_{\mathrm{EBG}}$ as a parameter. (c) Comparison between the $\mathrm{EAS}_{\mathrm{MD}-\mathrm{EBG}}\left(\mathrm{R}_{\mathrm{rmv}}=0.44\right.$, $\left.\mathrm{S}_{\mathrm{EBG}}=167 \mathrm{~mm}\right)$ and the $\mathrm{EAS}_{\mathrm{PEC}}\left(\mathrm{S}_{\mathrm{PEC}}=167 \mathrm{~mm}\right)$, both having the same thickness: $\mathrm{h}_{\mathrm{EBG}}+\mathrm{B}=\mathrm{h}_{\mathrm{PEC}}=9 \mathrm{~mm}$.

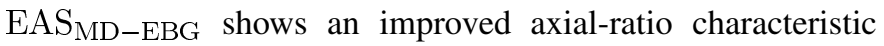
over a wide frequency range. This is confirmed by experimental work (white dots for $\mathrm{R}_{\mathrm{rmv}}=0.44$ ).

The starting edge of the remaining patches for $R_{\text {rmv }}=0.44$ is given as $\mathrm{r}_{\text {edge }}=56.50 \mathrm{~mm}$, which is slightly smaller than the spiral radius $\mathrm{r}_{\max }=56.86 \mathrm{~mm}$. As the removal ratio is further increased from $\mathrm{R}_{\mathrm{rmv}}=0.44$ (corresponding to $\mathrm{r}_{\max } / \mathrm{r}_{\text {edge }} \approx$ 
1), the axial ratio between 5 and $6 \mathrm{GHz}$ increases. In other words, the optimization of the EBG reflector for the axial ratio is finalized with $\mathrm{r}_{\max } / \mathrm{r}_{\text {edge }} \approx 1$. The radiation generated from the modified EBG reflector with $\mathrm{r}_{\text {max }} / \mathrm{r}_{\text {edge }} \approx 1$ is constructively added to that from the spiral.

Additional data on the axial ratio are presented in (b) and (c) of Fig. 10. Fig. 10(b) shows the axial ratio for $\mathrm{R}_{\mathrm{rmv}}=0.44$ (with $\mathrm{r}_{\max } / \mathrm{r}_{\text {edge }} \approx 1$ ) with the antenna height $\mathrm{h}_{\mathrm{EBG}}$ as a parameter, where the EBG side length remains unchanged $\left(\mathrm{S}_{\mathrm{EBG}}=167 \mathrm{~mm}\right)$. It is found that the frequency response curves of the axial ratio show a similar tendency. In addition, a comparison of the solid curve in Fig. 10(b) (where $\mathrm{R}_{\mathrm{rmv}}=0.44, \mathrm{~S}_{\mathrm{EBG}}=167 \mathrm{~mm}$, and $\mathrm{h}_{\mathrm{EBG}}=7 \mathrm{~mm}$ ) with the solid curve (b) in Fig. 7 (where $R_{\mathrm{rmv}}=0, \mathrm{~S}_{\mathrm{EBG}}=167 \mathrm{~mm}$, $\mathrm{h}_{\mathrm{EBG}}=7 \mathrm{~mm}$ ) reveals that the remaining patches contribute to an improvement in the axial ratios at frequencies between 5 and $6 \mathrm{GHz}$. Further comparison is made in Fig. 10(c), where the axial ratios of the EAS $\mathrm{MD-EBG}\left(\mathrm{R}_{\mathrm{rmv}}=0.44\right)$ and the EAS $\mathrm{PEC}_{\mathrm{P}}$ are compared, both having the same side length $\left(\mathrm{S}_{\mathrm{EBG}}=\mathrm{S}_{\mathrm{PEC}}=167 \mathrm{~mm}\right)$ and the same thickness $\left(\mathrm{h}_{\mathrm{EBG}}+\mathrm{B}=\mathrm{h}_{\mathrm{PEC}}=9 \mathrm{~mm}\right.$; the thickness is defined as the distance between the antenna arms and the bottom surface of the reflector; the antenna height has already been defined as the distance between the antenna arms and the upper surface of the reflector). It is revealed that the $\mathrm{EAS}_{\mathrm{MD}-\mathrm{EBG}}$ has improved axial ratios at frequencies between 5 and $6 \mathrm{GHz}$.

When a small axial ratio in the positive $\mathrm{z}$-direction is obtained, we expect that the radiation field around the positive z-axis will be circularly polarized. Fig. 11(a) shows the radiation pattern of the EAS $S_{M D-E B G}$. For comparison, the radiation pattern of the corresponding EAS $\mathrm{SEC}_{\mathrm{PE}}$ is also presented in Fig. 11(b), where the reflector side length and antenna height are chosen to be the same as those for the $\mathrm{EAS}_{\mathrm{MD}-\mathrm{EBG}}$ : $\mathrm{S}_{\mathrm{PEC}}=$ $\mathrm{S}_{\mathrm{EBG}}(=167 \mathrm{~mm})$ and $\mathrm{h}_{\mathrm{PEC}}=\mathrm{h}_{\mathrm{EBG}}(=7 \mathrm{~mm})$. We can clearly see that the radiation field from the EAS $\mathrm{SD}_{\mathrm{MDBG}}$ is circularly polarized around the positive $\mathrm{z}$-axis when the modified EBG reflector $\left(\mathrm{R}_{\mathrm{rmv}}=0.44\right)$ is used. Conversely, the EAS $\mathrm{SEC}_{\mathrm{PEC}}$ does not operate as a $\mathrm{CP}$ antenna. The validity of the analysis results for the $\mathrm{EAS}_{\mathrm{MD}-\mathrm{EBG}}$ is checked through experimental work; the experimental results (white and black dots) agree well with the theoretical results.

We further investigate the (total) radiation field for the EAS $_{M D-E B G}$ shown in Fig. 11(a). Using (3) and (4), this total radiation field is decomposed into two radiation field components. These are shown in the second and third rows in Fig. 12. It is found that the amplitude $\left|\mathrm{E}_{\mathrm{L}}\right|$ in the positive $\mathrm{z}$-direction is smaller than $\left|E_{R}\right|$, in contrast to the case shown in Fig. 8. In addition, it is confirmed that the phase difference between $\phi_{\mathrm{R}-\mathrm{EAS}}$ and $\phi_{\mathrm{R}-\mathrm{EBG}}$ in the positive z-direction for the case shown in Fig. 12 is smaller than that in Fig. 8 (approximately 90 degrees in Fig. 12 and approximately 180 degrees in Fig. 8). As a result, the axial ratio in the positive $\mathrm{z}$-direction is improved.

The improvement in the radiation field over a wide frequency range is due to a decrease in the cross-polarization component, which is produced by the in-coming current described in Section III-A. The decrease in the in-coming current reduces the effect on the current at the input terminals, which is given by the superposition of the out-going current and

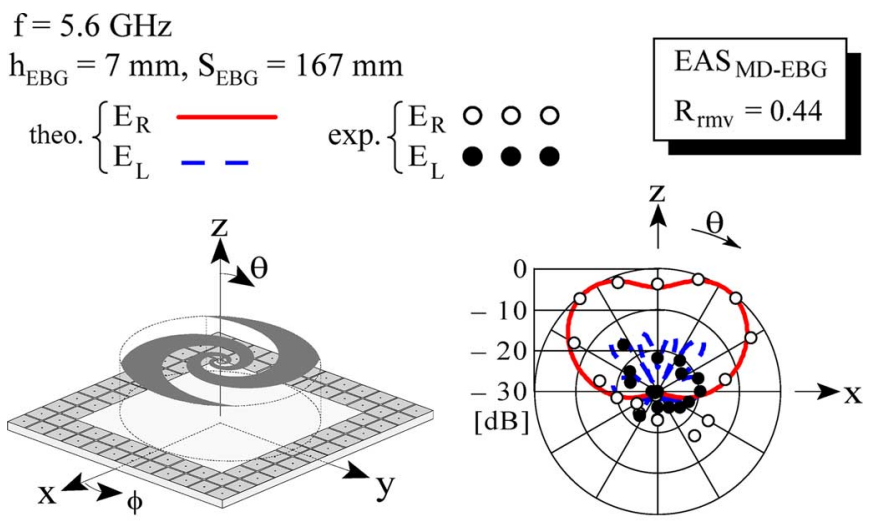

(a)
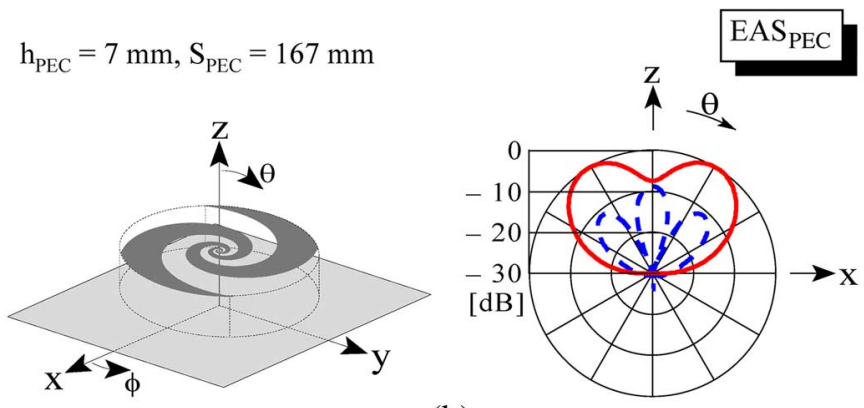

(b)

Fig. 11. Radiation patterns for the $\mathrm{EAS}_{\mathrm{MD}-\mathrm{EBG}}$ and the $\mathrm{EAS}_{\mathrm{PEC}}$ at 5.6 GHz, where $\mathrm{h}_{\mathrm{EBG}}=\mathrm{h}_{\mathrm{PEC}}=7 \mathrm{~mm}$ and $\mathrm{S}_{\mathrm{PEC}}=\mathrm{S}_{\mathrm{EBG}}=167 \mathrm{~mm}$. (a) $\mathrm{EAS}_{\mathrm{MD}-\mathrm{EBG}}$, where $\mathrm{R}_{\mathrm{rmv}}=0.44$ (for $\mathrm{N}_{\max }=12$ ), $\mathrm{f}_{\mathrm{EBG}}=$ $5.1 \mathrm{GHz} \equiv \mathrm{f}_{\mathrm{EBG} 2}, \mathrm{~s}=13 \mathrm{~mm}, \varepsilon_{\mathrm{r}}=2.2, \mathrm{~B}=2 \mathrm{~mm}$, and $\delta=1 \mathrm{~mm}$ (b) $\mathrm{EAS}_{\mathrm{PEC}}$

the in-coming current. As a result, the variation in the input impedance as a function of frequency for the EAS $S_{M D-E B G}$ becomes smaller than that for the EAS $\mathrm{PEC}_{\mathrm{PEC}}$, as shown in Fig. 13, where $\mathrm{h}_{\mathrm{EBG}}=\mathrm{h}_{\mathrm{PEC}}(=7 \mathrm{~mm}), \mathrm{S}_{\mathrm{EBG}}=\mathrm{S}_{\mathrm{PEC}}=\mathrm{S}_{\mathrm{PEC}, 0}$ $(=167 \mathrm{~mm})$, and $R_{\mathrm{rmv}}=0.44$. Note that the difference in the input impedances for the EAS $\mathrm{MD-EBG}$ and EASPEC at frequencies above $6 \mathrm{GHz}$ is negligibly small; this means that the modified EBG reflector acts as a PEC reflector at high frequencies, as expected from the reflection phase curve shown in Fig. 6, where the reflection phase approaches -180 degrees, as the frequency is increased.

In Fig. 13, experimental results (white dots) are added to the theoretical results for the $\mathrm{EAS}_{\mathrm{MD}-\mathrm{EBG}}$, for checking the validity of the analysis. The experiment is performed using bazooka baluns [16] (designed for each of eight frequencies of $3,4, \ldots$, and $10 \mathrm{GHz}$ ), due to the fact that an extremely small wideband balun has not yet been developed. The experimental and theoretical results are in good agreement.

Fig. 14 shows a comparison of the gains between the EAS $_{\mathrm{MD}-\mathrm{EBG}}\left(\mathrm{R}_{\mathrm{rmv}}=0.44, \mathrm{~h}_{\mathrm{EBG}}=7 \mathrm{~mm}\right.$, and $\left.\mathrm{S}_{\mathrm{EBG}}=167 \mathrm{~mm}\right)$ and the $\mathrm{EAS}_{\text {free }}$ isolated in free space without a reflector. The gain for the EAS $\mathrm{SD}_{\mathrm{EBG}}$ is greater than that for the $\mathrm{EAS}_{\text {free }}$ within the operating design frequency band $(4-9 \mathrm{GHz})$, due to the constructive reflection field from the modified EBG reflector. The experimental (white dots) and theoretical results are in good agreement. The gain drop for the 


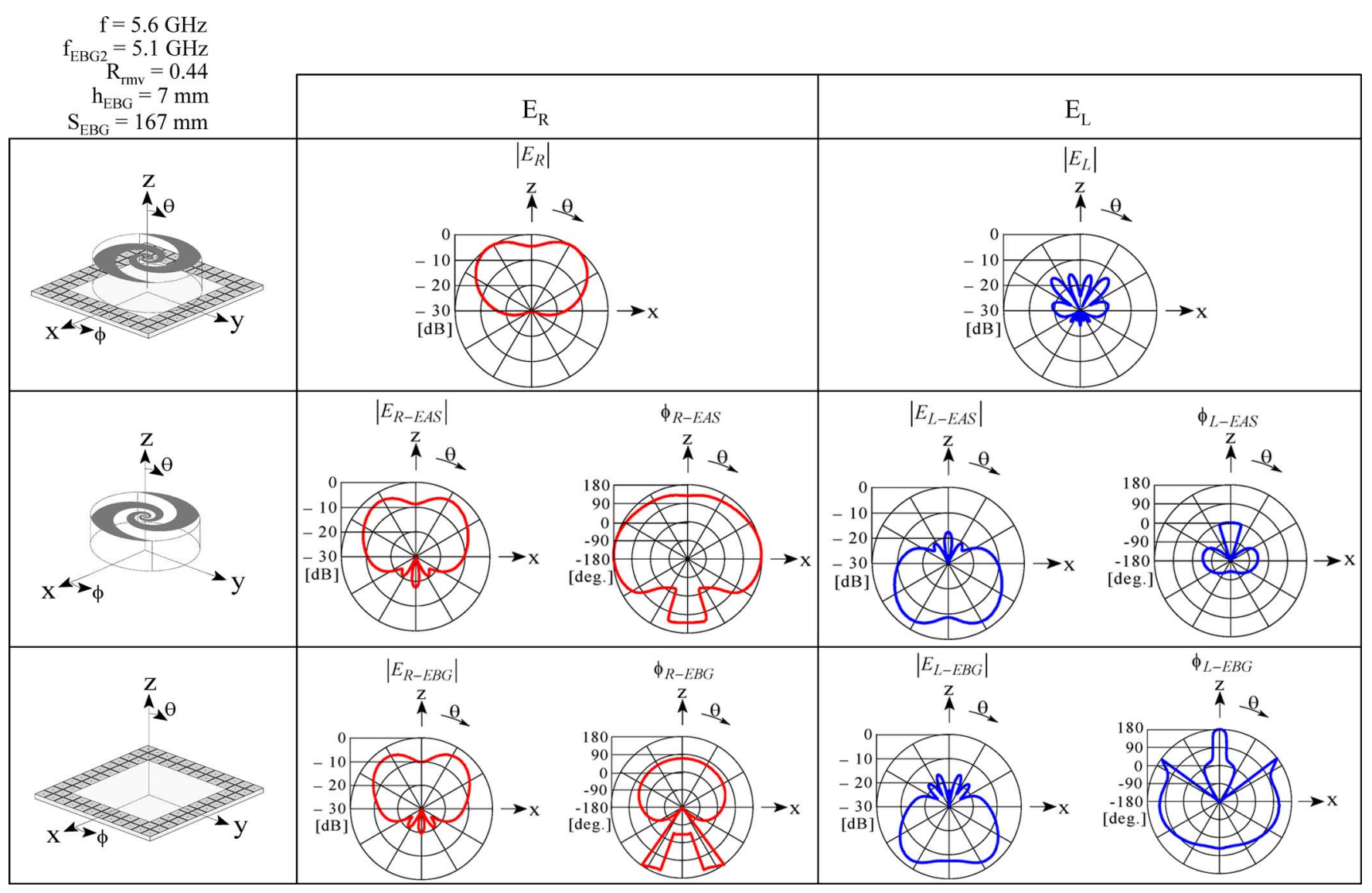

Fig. 12. Radiation field decomposition for the $\mathrm{EAS}_{\mathrm{MD}-\mathrm{EBG}}$ at $5.6 \mathrm{GHz}$, where $\mathrm{h}_{\mathrm{EBG}}=7 \mathrm{~mm}, \mathrm{~S}_{\mathrm{EBG}}=167 \mathrm{~mm}, \mathrm{f}_{\mathrm{EBG}}=5.1 \mathrm{GHz} \equiv \mathrm{f}_{\mathrm{EBG} 2}, \mathrm{~s}=13 \mathrm{~mm}$, $\varepsilon_{\mathrm{r}}=2.2, \mathrm{~B}=2 \mathrm{~mm}, \delta=1 \mathrm{~mm}$, and $\mathrm{R}_{\mathrm{rmv}}=0.44\left(\right.$ for $\mathrm{N}_{\max }=12$ ).

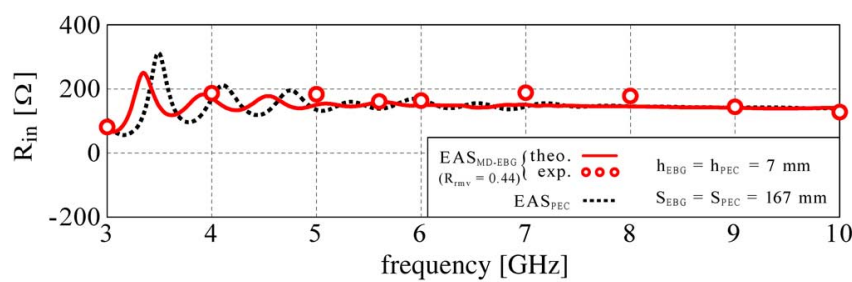

(a)

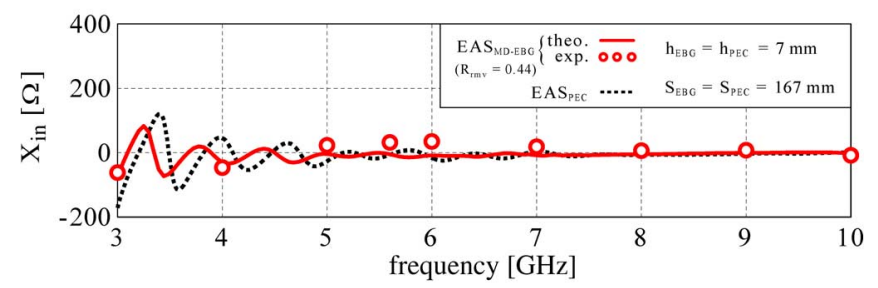

(b)

Fig. 13. Input impedances for the $E A S_{M D-E B G}$ and the $E_{A S_{P E C}}$, where $\mathrm{h}_{\mathrm{EBG}}=\mathrm{h}_{\mathrm{PEC}}=7 \mathrm{~mm}$ and $\mathrm{S}_{\mathrm{EBG}} \stackrel{\mathrm{M}}{=} \mathrm{S}_{\mathrm{PEC}}=167 \mathrm{~mm}$. Solid curve is for the $\mathrm{EAS}_{\mathrm{MD}-\mathrm{EBG}}$, where $\mathrm{R}_{\mathrm{rmv}}=0.44$ (for $\left.\mathrm{N}_{\max }=12\right), \mathrm{f}_{\mathrm{EBG}}=$ $5.1 \mathrm{GHz} \equiv \mathrm{f}_{\mathrm{EBG} 2}, \mathrm{~s}=13 \mathrm{~mm}, \varepsilon_{\mathrm{r}}=2.2, \mathrm{~B}=2 \mathrm{~mm}$, and $\delta=1 \mathrm{~mm}$. Dotted curve is for the EAS $\mathrm{SEC}_{\mathrm{PEC}}$.

$\mathrm{EAS}_{\mathrm{MD}-\mathrm{EBG}}$ around $5.6 \mathrm{GHz}$ results from a slight decrease in the radiation field in the z-direction, as shown in Fig. 11(a).

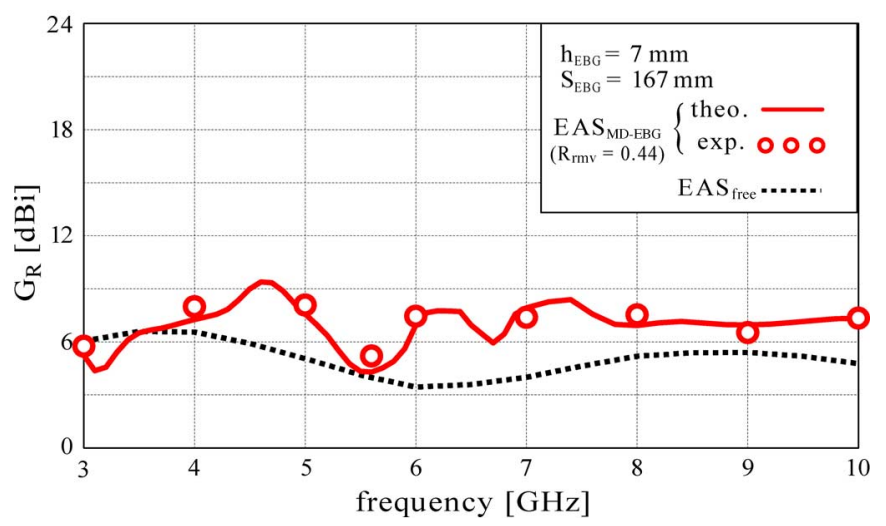

Fig. 14. Gains for the EAS $\mathrm{SD}_{\mathrm{MDBG}}$ and the $\mathrm{EAS}_{\mathrm{free}}$. Solid curve is for the $\mathrm{EAS}_{\mathrm{MD}-\mathrm{EBG}}$, where $\mathrm{h}_{\mathrm{EBG}}=7 \mathrm{~mm}, \mathrm{~S}_{\mathrm{EBG}}=167 \mathrm{~mm}, \mathrm{R}_{\mathrm{rmv}}=0.44$ (for $\mathrm{N}_{\max }=12$ ), $\mathrm{f}_{\mathrm{EBG}}=5.1 \mathrm{GHz} \equiv \mathrm{f}_{\mathrm{EBG} 2}, \mathrm{~s}=13 \mathrm{~mm}, \varepsilon_{\mathrm{r}}=2.2$, $\mathrm{B}=2 \mathrm{~mm}$, and $\delta=1 \mathrm{~mm}$. Dotted curve is for the $\operatorname{EAS}_{\text {free }}$.

\section{CONCLUSION}

An equiangular spiral antenna backed by a PEC reflector $\left(E_{P A C}\right)$ is analyzed under the condition that the antenna height is extremely small ( 0.07 wavelength at the lowest analysis frequency of $3 \mathrm{GHz}$ ). The analysis shows that the inherent wideband axial ratio obtained when the equiangular spiral is isolated in free space $\left(\mathrm{EAS}_{\text {free }}\right)$ is not reproduced. This is 
attributed to the standing wave behavior of the current along the spiral arms.

In an attempt to improve the axial ratio, the PEC reflector is replaced with an EBG reflector. However, this antenna $\left(\mathrm{EAS}_{\mathrm{EBG}}\right)$ does not exhibit small axial ratios over a wide frequency range. The undesirably large axial ratio for the EAS $_{\mathrm{EBG}}$ is explained using the two radiation field components that constitute the total radiation field: one component from the equiangular spiral and the other from the EBG reflector. The large axial ratio results from the fact that the amplitudes and phases of these two radiation field components do not have a constructive relationship necessary for $\mathrm{CP}$ radiation.

Based on the abovementioned finding, the EBG reflector is modified in an attempt to satisfy or approximate the constructive relationship necessary for $\mathrm{CP}$ radiation. This is performed by gradually removing the patch elements of the EBG reflector from the center region of the reflector, thereby reducing the mutual coupling between the antenna arms and EBG reflector. It is found that this equiangular spiral with a modified EBG reflector $\left(\mathrm{EAS}_{\mathrm{MD}-\mathrm{EBG}}\right)$ has, within the operating design frequency band (4-9 GHz), small axial ratio and relatively constant input impedance characteristics.

\section{ACKNOWLEDGMENT}

The authors thank V. Shkawrytko and H. Mimaki for their assistance in the preparation of this manuscript.

\section{REFERENCES}

[1] J. Dyson, "Equiangular spiral antenna," IRE Trans. Antennas Propag., vol. 7, no. 2, pp. 181-187, Apr. 1959.

[2] H. Nakano, "Recent progress in broadband antenna," in Int. Symp. on Antennas Propag., Singapore, Nov. 2006, [CDROM] a367 r66.

[3] D. Sievenpiper, L. Zhang, R. F. J. Broas, N. G. Alexopoulos, and E. Yablonovich, "High-impedance electromagnetic surfaces with a forbidden frequency band," IEEE Trans. Microw. Theory Tech., vol. 47, no. 11, pp. 2059-2074, Nov. 1999.

[4] K. S. Yee, "Numerical solution of initial boundary value problems involving Maxwell's equations in isotropic media," IEEE Trans. Antennas Propag., vol. AP-14, pp. 302-307, May 1966.

[5] H. Nakano, M. Sakurai, N. Tatsuzawa, and J. Yamauchi, "A dual-frequency spiral antenna," in Proc. IEICE Conf., Sendai, Japan, Mar. 2003, p. B-1-135.

[6] D. Qu, L. Shafai, and A. Foroozesh, "Improving microstrip patch antenna performance using EBG substrates," Proc. Inst. Elect. Eng. Microw. Antennas Propag., vol. 153, no. 6, pp. 558-563, Dec. 2006.

[7] F. Yang, H. Mosallaei, and Y. Rahmat-Samii, Antenna Engineering Handbook, J. Volakis, Ed., 4th ed. Englewood Cliffs, NJ: McGrawHill, Jun. 2007, ch. 34.

[8] Y. Mushiake, Self-Complementary Antennas. London, U.K.: Springer, 1996.

[9] J. A. Kaiser, "The Archimedean two-wire spiral antenna," IRE Trans. Antennas Propag., vol. AP-8, pp. 312-323, May 1960.

[10] T. Uno, Finite Difference Time Domain Method for Electromagnetic Field and Antenna Analyses (in Japanese). Tokyo, Japan: Corona, 1998.

[11] R. Harrington, Time-Harmonic Electromagnetic Fields. New York: McGraw-Hill, 1961, pp. 106-110.

[12] H. Nakano, K. Nogami, S. Arai, H. Mimaki, and J. Yamauchi, “A spiral antenna backed by a conducting plane reflector," IEEE Trans. Antennas Propag., vol. AP. 34, no. 6, pp. 791-796, Jun. 1986.

[13] J. J. H. Wang, "The spiral as a traveling wave structure for broadband antenna applications," Electromagnetics, vol. 20, no. 4, pp. 323-342, Jul. 2000.
[14] F. Yang and Y. Rahmat-Samii, "A low-profile circularly polarized curl antenna over electromagnetic band-gap (EBG) surface," Microw. Opt. Technol. Lett., vol. 31, no. 4, pp. 264-267, Nov. 2001.

[15] H. Nakano, K. Hitosugi, N. Tatsuzawa, D. Togashi, H. Mimaki, and J. Yamauchi, "Effects on the radiation characteristics of using a corrugated reflector with a helical antenna and an electromagnetic band-gap reflector with a spiral antenna," IEEE Trans. Antennas Propag., vol. 53, no. 1, pp. 191-199, January 2005.

[16] R. C. Johnson and H. Jasik, Antenna Engineering Handbook, 2nd ed. New York: McGraw-Hill, 1984, pp. 43-23-43-31.

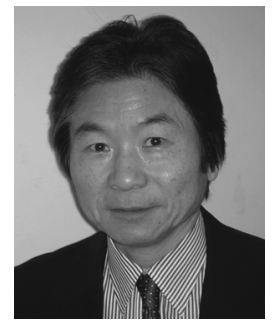

Hisamatsu Nakano (M'75-SM'87-F'92) was born in Japan. He received the B.E., M.E., and Dr.E. degrees in electrical engineering from Hosei University, Tokyo, Japan, in 1968, 1970, and 1974, respectively.

Since 1973, he has been a member of the faculty at Hosei University, where he is now a Professor of electronic informatics. His research topics include numerical methods for low- and high-frequency antennas and optical waveguides. He has published more than 230 refereed journal papers, more than 270 international symposium papers, and more than 870 national symposium papers. He is the author of a book entitled Helical and Spiral Antennas (Hertfordshire, U.K.: Research Studies Press, 1987) and the coauthor of several books, including Analysis Methods of Electromagnetic Wave Problems (Norwood, MA: Artech House, 1986), Encyclopedia of Communications (New York: Wiley, 2002), and Modern Antenna Handbook (New York: Wiley, 2008). He is an inventor of planar and parabolic antennas for a direct broadcasting satellite receiving antenna. $\mathrm{He}$ is also an inventor of a fan-shaped antenna and a low-profile BOR-SPR antenna for UWB systems.

Prof. Nakano received the IEE International Conference on Antennas and Propagation Best Paper Award and the IEEE TRANSACTIONS ON ANTENNAS AND Propagation Best Application Paper Award (H. A. Wheeler Award) in 1989 and 1994, respectively. In 1992, he was elected an IEEE fellow for his contributions to the design of spiral and helical antennas. In 2001, he received the Award of Distinguished Technical Communication (from the Society for Technical Communication, USA). He was the recipient of the Chen-To Tai Distinguished Educator Award (from the IEEE Antennas and Propagation Society) in 2006. He is an Associate Editor of several journals and magazines, such as Electromagnetics, the IEEE Antennas and Propagation Magazine, IEEE ANTENNAS AND WiRELESS PROPAGATION LETTERS, and Asian Information-Science-Life. He was a member of the IEEE AP-S AdCom (2000-2002) and is currently serving as an IEEE AP-S region 10 representative.

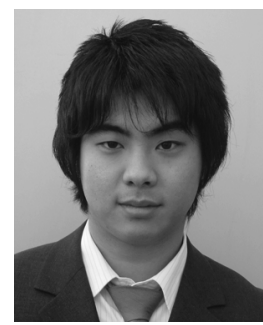

Katsuki Kikkawa received the B.E. and M.E. degrees in electronic informatics from Hosei University, Tokyo, Japan, in 2006 and 2008, respectively.

He is currently with Yokogawa Electric Corporation, Tokyo, Japan.

Mr. Kikkawa is a member of the Institute of Electronics, Information, and Communication Engineers (IEICE) of Japan.

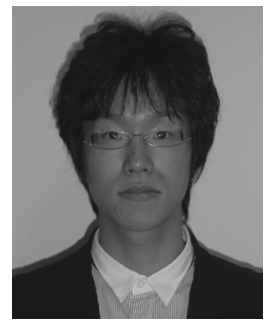

Norihiro Kondo is an undergraduate student at Hose University, Tokyo, Japan.

$\mathrm{He}$ is currently with Nakano Laboratory, Hosei University.

Mr. Kondo is a student member of the Institute of Electronics, Information, and Communication Engineers (IEICE) of Japan. 


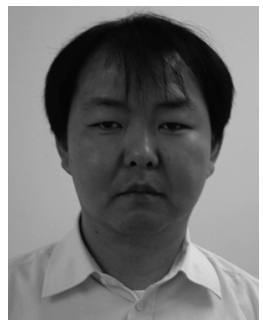

Yasushi Iitsuka (M'98) was born in Ibaraki, Japan, on July 16, 1968. He received the B.E. degree in communication engineering and the M.E. degree in electrical engineering from Tokai University, Kanagawa, Japan, in 1992 and 1994, respectively. He is currently working toward the Ph.D. degree at Hosei University, Tokyo, Japan.

From 1994 to 2004, he was with Antenna Giken Co., Ltd., Saitama, Japan and, from 2004 to 2006, was with Samsung Electro-Mechanics Co., Ltd., Suwon, South Korea. His current research interests are the design and analysis of antennas for mobile and satellite communication system.

Mr. Iitsuka is a member of the Institute of Electronics, Information, and Communication Engineers (IEICE) of Japan.

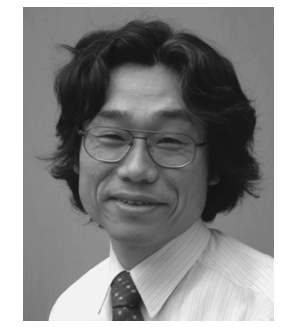

Junji Yamauchi (M'84) was born in Nagoya, Japan, on August 23, 1953. He received the B.E., M.E., and Dr.E. degrees from Hosei University, Tokyo, Japan, in 1976, 1978, and 1982, respectively.

From 1984 to 1988, he served as a Lecturer in the Electrical Engineering Department of Tokyo Metropolitan Technical College. Since 1988, he has been a member of the faculty of Hosei University, where he is now a Professor of electronic informatics. His research interests include optical waveguides and circularly polarized antennas. $\mathrm{He}$ is the author of Propagating Beam Analysis of Optical Waveguides (Baldock, Hertfordshire, U.K.: Research Studies Press, 2003).

Dr. Yamauchi is a member of the Optical Society of America and the Institute of Electronics, Information and Communication Engineers of Japan. 